\title{
Cut, Repair, Stitch - How Close Are We to Molecular Surgery Performed Using Genome Editing Techniques?
}

\section{Yichi (Tony) Zhang, ${ }^{a}$ Aaron MacCoshamb}

anstitute of Biochemistry and Department of Biology, Carleton University

${ }^{b}$ Department of Biology, University of Ottawa

\section{Introduction}

We are currently on the cusp of being able to perform molecular surgery, where nucleases cut out disease mutations, and correct nucleotide sequences can be stitched back together to repair genes (1). Molecular surgery has the potential to facilitate treatment or completely cure diseases with a genetic basis. This has been made possible due to the evolution of genomic editing with the development of zinc finger nucleases (ZFNs), then transcription activator-like effector nucleases (TALENs), and finally clustered regularly interspaced short palindromic repeat (CRISPR)-associated Cas9 nucleases (1). All three methods enable their respective nucleases (either Fokl or Cas9) to introduce double-strand breaks (DSBs) in DNA at specific genomic loci. Afterwards, DNA repair occurs via either non-homologous end-joining (NHEJ) or homology-directed repair/homologous recombination (HDR/HR) (1). While key differences between these techniques exist (Table 1), the simplicity, reproducibility, and affordability of CRISPR/Cas9 have made it the most commonly used technique. This is mainly due to the use of guide nucleotides for Cas9, compared with the protein engineering that is required for the other two methods. Therefore, this review will focus on CRISPR/ Cas9 in terms of its impact on clinical research, its limitations and potential solutions, and clinical applications

Table I: Comparison of the three main genome-editing platforms.

\begin{tabular}{|c|c|c|c|}
\hline & ZFN & TALEN & CRISPR/Cas9 \\
\hline Nuclease & Fokl & Fokl & Cas9 \\
\hline Construction & $\begin{array}{l}\text { Difficult. Protein } \\
\text { engineering required for } \\
\text { every target. }\end{array}$ & $\begin{array}{l}\text { Moderate. Protein engineering, } \\
\text { complex cloning methods required. }\end{array}$ & $\begin{array}{l}\text { Easy. } 20 \text {-nucleotide guide RNA } \\
\text { required. Easily re-targeted using } \\
\text { simple cloning procedures. }\end{array}$ \\
\hline $\begin{array}{l}\text { Required } \\
\text { Components }\end{array}$ & $\begin{array}{l}\text { Two ZFNs needed around } \\
\text { the target sequence. }\end{array}$ & $\begin{array}{l}\text { Two TALENs needed around the } \\
\text { target sequence. }\end{array}$ & $\begin{array}{l}\text { Guide RNA complementary to the } \\
\text { target sequence with one Cas } 9 \text {. }\end{array}$ \\
\hline Multiplexing & Challenging. & Challenging. & Possible. \\
\hline $\begin{array}{l}\text { Feasibility of } \\
\text { genome-wide } \\
\text { screens }\end{array}$ & Challenging. & Challenging. & Possible. \\
\hline Affordability & $\begin{array}{l}\text { Very costly and time } \\
\text { consuming. }\end{array}$ & Affordable, but time consuming. & Very affordable. \\
\hline $\begin{array}{l}\text { Targeting } \\
\text { constraints }\end{array}$ & $\begin{array}{l}\text { Difficult to target non- } \\
\text { guanosine-rich sequences. }\end{array}$ & $\begin{array}{l}5 \text { ' targeted base must be a tyrosine } \\
\text { for each TALEN monomer. }\end{array}$ & $\begin{array}{l}\text { Targeted sequence must precede a } \\
\text { protospacer-associated motif (PAM) } \\
\text { NGG sequence. }\end{array}$ \\
\hline Ex vivo delivery & $\begin{array}{l}\text { Relatively easy through } \\
\text { electroporation and viral } \\
\text { transduction, for example. }\end{array}$ & $\begin{array}{l}\text { Relatively easy through } \\
\text { electroporation and viral } \\
\text { transduction, for example. }\end{array}$ & $\begin{array}{l}\text { Relatively easy through } \\
\text { electroporation and viral } \\
\text { transduction, for example. }\end{array}$ \\
\hline In vivo delivery & $\begin{array}{l}\text { Relatively easy since ZFN } \\
\text { expression cassettes are } \\
\text { small enough to be } \\
\text { contained in viral vectors. }\end{array}$ & $\begin{array}{l}\text { Difficult, as each TALEN and the } \\
\text { repetitive nature of DNA-encoding } \\
\text { TALENs are large, so unwanted } \\
\text { recombination occurs in lentiviral } \\
\text { vectors. }\end{array}$ & $\begin{array}{l}\text { Moderate. The most commonly used } \\
\text { Cas9 from S. pyogenes bacteria is } \\
\text { large and imposes problems } \\
\text { packaging for viral vectors. Smaller } \\
\text { orthologs exist. }\end{array}$ \\
\hline
\end{tabular}


$\varepsilon \quad$ of genomic editing to humans.

\section{The future of genomic editing in scientific research - challenges and innovative solutions}

Genomic editing has already facilitated the development of new disease models and the identification of novel drug targets. For instance, the applicability of disease studies on animal models greatly improved when genome editing was used to efficiently create primate models that closely resemble humans (2). To identify novel therapeutic targets for drug development, screening studies using CRISPR/Cas9 are being conducted to identify specific pathways used by diseased cells (3).

Despite recent advances, the issues of efficacy, safety, delivery, and ethics continue to prevent genome editing from being applied clinically. In terms of efficacy, NHEJ-mediated DNA repair efficiently cuts and stitches diseased genes at any point in the cell cycle, but if insertions are required then repair could be slowed, as HDR is only available during certain cell cycle phases. Safety is a concern, especially for CRISPR/Cas9, due to off-target mutations that result from Cas9 nucleases occasionally cutting non-specifically. This presents dangers to humans if harmful mutations are introduced, even at a low rate (4). Another challenge involves the delivery of editing components to all cells, while avoiding immune response, should viruses be used for delivery. Lastly, due to the ability of this technology to genetically alter individuals and their offspring, many ethical issues are raised regarding editing human embryos $(1,5)$.

In order to address the above-mentioned challenges, NHEJ-mediated ligation of DNA templates could be used to increase the rate of recombination if Cas9 is modified to generate sticky ends in DNA (5). Many solutions are being researched to address the off-target effects of Cas9. For example, using a Cas9 nickase mutant to simultaneously nick both DNA strands, fusing inactive Cas9 to Fokl, and using a small-molecule-triggered Cas9, all increase the specificity of cutting individually and in combination $(6,7)$. The delivery of these additional components further stresses the necessity of non-viral delivery systems, as viral vectors are small. Therefore, nanoparticle- and lipid-based delivery systems are under development $(8,9)$. Policymakers evaluating the ethics of this technology should be particularly concerned about the dangers of off-target effects associated with CRISPR/Cas9. However, many patients suffering from incurable diseases like Duchenne Muscular Dystrophy (DMD) are desperate for a cure. Therefore, policymakers should take the patient's wishes into consideration as well. Currently, only four countries have approved the use of genome editing on human embryos, a process known as germline editing. Governments are understandably reluctant to move forward with germline editing for fear of genetic testing to enhance human performance, and opening the debate regarding when and if human embryos are considered living humans.

\section{Clinical applications of CRISPR/Cas9 and other gene editing methods to humans}

As previously mentioned, genomic editing has yet to be translated to clinical application. However, it is very close to being used to treat infectious diseases like HIV. In fact, genomic editing of $\mathrm{CD}^{+} \mathrm{T}$ cells to generate cells resistant to HIV infection has already reached phase II clinical trials (10). Highly publicized cancer trials using CRISPR/Cas9 are also underway. However, many currently incurable diseases like DMD and cystic fibrosis require germline editing, and that is where genome editing can have the greatest impact in the near future $(1,2)$.

\section{Conclusion}

The tremendous excitement around genome editing and the idea of molecular surgery - taking any disease, removing causative mutations, and stitching DNA back together to leave the cell unharmed - is warranted given recent progress. However, issues around efficiency, safety, delivery, and ethics must still be resolved. The ethics of using genomic editing on human embryos needs to be addressed carefully. Given that only four countries have approved germline editing using CRISPR/ Cas9, policymakers are understandably reluctant moving forward. However, the success of current clinical trials may convince regulatory bodies to use genome editing to its full potential.

\section{References}

1. Eid A, Mahfouz MM. Genome editing: the road of CRISPR/Cas9 from bench to clinic. Exp Mol Med. 2016;48(10):e265.

2. Chen $\mathrm{Y}$, Zheng $\mathrm{Y}$, Kang $\mathrm{Y}$, Yang $\mathrm{W}$, Niu Y, Guo X, et al. Functional disruption of the dystrophin gene in rhesus monkey using CRISPR/Cas9. Hum Mol Genet. 2015;24(13):3764-74.

3. Sachdeva M, Sachdeva N, Pal M, Gupta N, Khan IA, Majumdar $\mathrm{M}$, et al. CRISPR/Cas9: molecular tool for gene therapy to target genome and epigenome in the treatment of lung cancer. Cancer Gene Ther. 2015;22(11):509-17.

4. Veres A, Gosis BS, Ding Q, Collins R, Ragavendran A, Brand H, et al. Low incidence of off-target mutations in individual CRISPRCas 9 and TALEN targeted human stem cell clones detected by whole-genome sequencing. Cell Stem Cell. 2014;15(1):27-30.

5. Cox DBT, Platt RJ, Zhang F. Therapeutic genome editing: prospects and challenges. Nat Med. 2015;21(2):121-31.

6. Guilinger JP, Thompson DB, Liu DR. Fusion of catalytically inactive Cas9 to Fokl nuclease improves the specificity of genome modification. Nat Biotechnol. 2014;32(6):577-82.

7. Davis KM, Pattanayak V, Thompson DB, Zuris JA, Liu DR. Small molecule-triggered Cas9 protein with improved genome-editing specificity. Nat Chem Biol. 2015;11(5):316-8.

8. Zuris JA, Thompson DB, Shu Y, Guilinger JP, Bessen JL, Hu JH, et al. Cationic lipid-mediated delivery of proteins enables efficient protein-based genome editing in vitro and in vivo. Nat Biotechnol. 2014;33(1):73-80.

9. Kormann MSD, Hasenpusch G, Aneja MK, Nica G, Flemmer AW, 
Herber-Jonat S, et al. Expression of therapeutic proteins after delivery of chemically modified mRNA in mice. Nat Biotechnol. 2011;29(2):154-7.

10. Tebas P, Stein D, Tang WW, Frank I, Wang SQ, Lee G, et al. Gene editing of CCR5 in autologous CD4 T cells of persons infected with HIV. N Engl J Med. 2014;370(10):901-10.

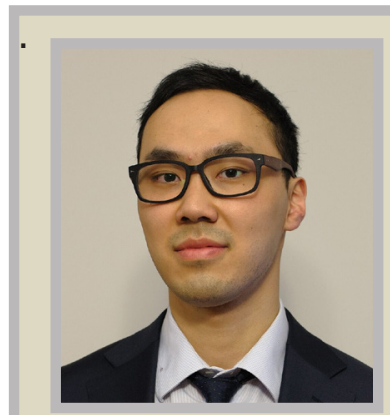

\section{Yichi (Tony) Zhang}

Tony completed his BSc in Kinesiology at Queen's University and is completing his MSc at Carleton University in the Department of Biology. His research focusses on the comparison between skeletal and cardiac muscle in thirteen-lined ground squirrels. These animals hibernate during winter months, where they demonstrate a remarkable capability to preserve their muscle mass despite prolonged periods of inactivity. They also undergo reversible cardiac hypertrophy during hibernation. Understanding these physiological adaptations has clinical implications in the development of new treatments for muscle-wasting diseases.

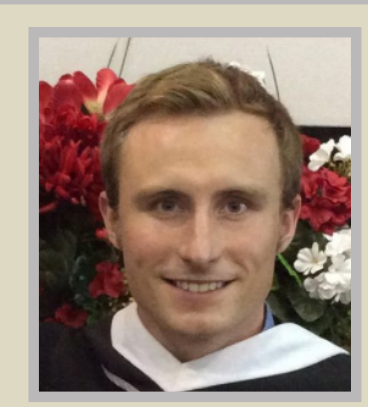

\section{Aaron MacCosham}

Aaron received his BA in Psychology from Carleton University and is currently pursuing a BSc in Biomedical Sciences from the University of Ottawa. At present, he is the Co-Chair of Conferences and Workshops for the Canadian Society of Epidemiology and Biostatistics - University of Ottawa. 